\title{
CHATTER-FREE NONLINEAR CONTROL OF DFIG POWER FOR WIND CONVERSION SYSTEM
}

\author{
Abdelhaq Amar Bensaber ${ }^{1}$, Mustapha Benghanem ${ }^{1}$ and Mohamed Bourahla ${ }^{1}$ \\ ${ }^{1}$ University of Science and Technology of Oran - Mohamed-Boudiaf- \\ 1abs.abdelhak@gmail.com,mbenghanem6@yahoo.fr, bourah@yahoo.fr
}

\begin{abstract}
In this paper, a robust nonlinear controller based on sliding mode control strategy is adopted for a variable-speed wind energy conversion system with a double-fed asynchronous generator (DFIG). Firstly, field-oriented control law based on PI controllers has been introduced. However, wind turbines components work as nonlinear systems where electromechanical parameters change considerably; thus, a SOSMC with a simple function to smooth control signals is introduced, the aim of the proposed controller is to contributes with some important features such as power fineness, minimize the chattering, ameliorate respond time and deal with grid requirements. Matlab tests are introduced in an attempt to confirm the effectiveness of the proposed control.
\end{abstract}

Keywords-SOSMC, DFIG, SMC, wind turbines

\section{INTRODUCTION}

Nowadays, Wind energy is the brightest renewable source of electrical power generation for the future; it has been proved as one acknowledged potential source of energy. Compared with other clean energies like it cost efficiency and reliability [1-5]. Thus, those factors became important topics in industry and research [6, 7]. Control strategies are necessary to attain maximum performance. The DFIG WTs has been an attractive choice $[8,9]$ because of to the independent power control plus it ability to deal with variable speed due to control of back-to-back converter scheme[10, 11], reduced mechanical stresses[2], recompense for power pulsations and torque [12] and improve power quality[2], the major feature of proposed generator is that the power converter is sized between "20-30\%" of entire power which means the cost is reduced[13], still the generator respond to voltage disturbances is critical, as expressed in $[2,14]$, ,to protect and remain connected to the network even with faults it is required to control the rotor converter. [2, 14-16], the control schemes are established with the vector control with the classical controller, but this controller can provide favorable performance restrictive under ideal voltage conditions. Furthermore, disturbances and parameter variations will leave us with imperfect performance. Therefore, papers have offered many control strategies for DFIG like Sliding Mode Control, smart control or adaptive algorithms [1, 17, 18], HOSMC [6, 15, 16, 19, 20]. SMC, despite robust, it suffers two main deficiencies. First, chattering phenomena which produced from the high-frequency switching that damage the performance and excites high frequency oscillations [21, 22], In an attempt to overthrow these problems, many authors proposed to modify the SMC law $[15,19]$.

In this present paper, SMC is suggested to regulate the power swapped between the generator and the grid, to overcome it drawbacks many of methods were proposed like

Received: March 22, 2019

Reviewed: April 26, 2019

Accepted: May 13, 2019 
approximating the sign function by a high gain saturation function [16], we decide to use SOMC because it has several features like:

- Robustness [22, 20].

- Subtraction of mechanical stresses and chattering [22].

- Easy to implement.

We propose an improvement to the $2 \mathrm{SMC}$ by adjusting the discontinuous control signal toward sliding surface and we used the three phase matrix converter because:

- Provides bidirectional energy flow

- Nearly sinusoidal input/output waveforms

- Controllable input power factor.

\section{MODEL OF THE TURBINE}

The power contained in kinetic energy form at a speed $V v$, surface $A 1$, is expressed by

$$
P_{v}=\frac{1}{2} \rho A_{1} V_{v}^{3}
$$

Where $\rho$ is the air density.

The wind turbine can recover only a part of that power:

$$
P_{v}=\frac{1}{2} \rho \pi R^{2} V_{v}^{3} C_{p}
$$

Where: $\mathrm{R}$ is the radius; $\mathrm{Cp}$ is power coefficient [11], this coefficient is a related with the wind and wind turbine rotation pace and the pitch angle. The speed ratio $\lambda$ introduced by

$$
\lambda=\frac{R \Omega_{t}}{V_{v}}
$$

Knowing the speed of rotation of the turbine, the mechanical torque $\mathrm{Ct}$ available on the slow shaft of the turbine can be expressed by:

$$
C_{t}=\frac{P_{t}}{\Omega_{t}}=\frac{\pi}{2 \lambda} \rho R^{3} v^{2} C_{p}
$$

2.1. MECHANICAL SYSTEM: The mechanical model will be illustrated in Figure 1.

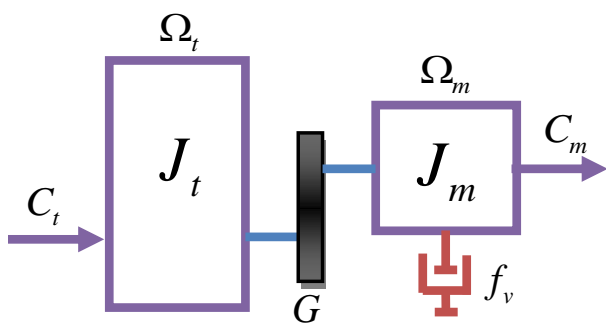

Fig. 1 Mechanical Model

Where: Jt: the turbine inertia, while Jm: generator inertia, G is the gearbox ratio. The generator speed and the fast shaft torque are given in: 


$$
\begin{gathered}
\Omega_{m}=G \Omega_{t} \\
C_{m}=C_{t} / G
\end{gathered}
$$

Next,

$$
C_{m}-C_{e m}=\left(\frac{J_{t}}{G^{2}}+J_{m}\right) \frac{d \Omega_{m}}{d t}+f_{v} \Omega_{m}
$$

\section{THE MATRIX CONVERTER MODEL}

It can be considered as the simplest structure due to the lake of the dc link; it composed of a matrix of bidirectional switches linking two independent three-phase systems as shown in Fig. 2 shows the diagram of a matrix converter. Smn is given by:

$$
S_{m n}=\left\{\begin{array}{lll}
1 & S_{m n} & \text { closed } \\
0 & S_{m n} & \text { open }
\end{array} \quad m \in\{A, B, C\}, n \in\{a, b, c\}\right.
$$

The mathematical expression of the matrix converter can be written as:

$$
\begin{aligned}
& {\left[\begin{array}{c}
V_{a} \\
V_{b} \\
V_{c}
\end{array}\right]=\left[\begin{array}{lll}
S_{A a} & S_{A b} & S_{A c} \\
S_{B a} & S_{B b} & S_{B c} \\
S_{C a} & S_{C b} & S_{C c}
\end{array}\right]\left[\begin{array}{c}
V_{A} \\
V_{B} \\
V_{C}
\end{array}\right]} \\
& {\left[\begin{array}{c}
i_{A} \\
i_{B} \\
i_{C}
\end{array}\right]=\left[\begin{array}{lll}
S_{A a} & S_{B a} & S_{C a} \\
S_{A b} & S_{B b} & S_{C b} \\
S_{A c} & S_{B c} & S_{C c}
\end{array}\right]^{T}\left[\begin{array}{l}
i_{a} \\
i_{b} \\
i_{c}
\end{array}\right]}
\end{aligned}
$$

The input/output relationships of voltages and currents are related to the states of the nine switches and can be expressed as follows:

$$
\begin{aligned}
& {\left[\begin{array}{l}
V_{a} \\
V_{b} \\
V_{c}
\end{array}\right]=\left[\begin{array}{lll}
k_{A a} & k_{A b} & k_{A c} \\
k_{B a} & k_{B b} & k_{B c} \\
k_{C a} & k_{C b} & k_{C c}
\end{array}\right]\left[\begin{array}{l}
V_{A} \\
V_{B} \\
V_{C}
\end{array}\right]} \\
& {\left[\begin{array}{l}
i_{A} \\
i_{B} \\
i_{C}
\end{array}\right]=\left[\begin{array}{lll}
k_{A a} & k_{B a} & k_{C a} \\
k_{A b} & k_{B b} & k_{C b} \\
k_{A c} & k_{B c} & k_{C c}
\end{array}\right]^{T}\left[\begin{array}{l}
i_{a} \\
i_{b} \\
i_{c}
\end{array}\right]}
\end{aligned}
$$

With:

$$
0 \leq k_{m n} \leq 1, m=A, B, C, n=a, b, c
$$

kmn are the duty cycles of the switches, these duty cycles must satisfy the three following constraint conditions to prevent a short circuit:

$$
\left\{\begin{array}{l}
k_{A a}+k_{A b}+k_{A c}=1 \\
k_{B a}+k_{B b}+k_{B c}=1 \\
k_{C a}+k_{C b}+k_{C c}=1
\end{array}\right.
$$


The output voltage is given by:

$$
\left[\begin{array}{l}
V_{a} \\
V_{b} \\
V_{c}
\end{array}\right]=\left[\begin{array}{ccc}
1+2 \delta \cos a & 1+2 \delta \cos \left(a-\frac{2 \pi}{3}\right) & 1+2 \delta \cos \left(a-\frac{4 \pi}{3}\right) \\
1+2 \delta \cos \left(a-\frac{4 \pi}{3}\right) & 1+2 \delta \cos a & 1+2 \delta \cos \left(a-\frac{2 \pi}{3}\right) \\
1+2 \delta \cos \left(a-\frac{2 \pi}{3}\right) & 1+2 \delta \cos \left(a-\frac{4 \pi}{3}\right) & 1+2 \delta \cos a
\end{array}\right]\left[\begin{array}{l}
V_{A} \\
V_{B} \\
V_{C}
\end{array}\right]
$$

Where:

$$
\left\{\begin{array}{l}
a=\omega_{m}+\theta \\
\omega_{m}=\omega_{\text {output }}-\omega_{\text {input }}
\end{array}\right.
$$

The running matrix converter with Venturini algorithm generates at the output a threephases sinusoidal voltages system having in that order pulsation $\omega \mathrm{m}$, a phase angle $\theta$ and amplitude $\delta$.Vs $(0<\delta<0.866$ with modulation of the neural).

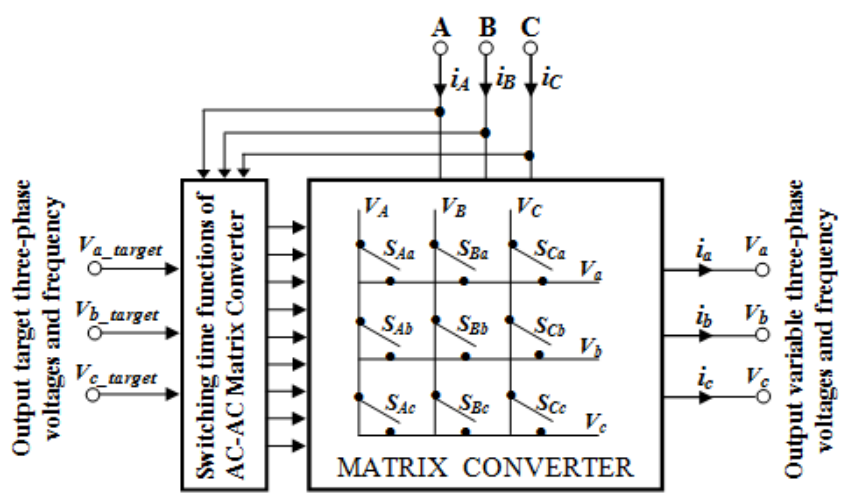

Fig 2 The Matrix Converter

\section{MATHEMATICAL MODEL OF DFIG:}

We have chosen to use the double-fed induction generator because with the help of the bidirectional converter in the rotor it is possible to work in both sub-synchronous and super-synchronous. The electrical model of the machine obtained using Park transformation is given by the following equations:

Stator, rotor voltages:

$$
\begin{gathered}
V_{q s}=R_{s} I_{q s}+\frac{d \phi_{q s}}{d t}-\omega_{s} \phi_{d s} \\
V_{d r}=R_{r} I_{d r}+\frac{d \phi_{d r}}{d t}-\omega \phi_{q r}
\end{gathered}
$$

$$
\begin{aligned}
& V_{d s}=R_{s} I_{d s}+\frac{d \phi_{d s}}{d t}-\omega_{s} \phi_{q s} \\
& V_{q r}=R_{r} I_{q r}+\frac{d \phi_{q r}}{d t}-\omega \phi_{d r}
\end{aligned}
$$

\section{THE DFIG VECTOR CONTROL:}

In this section, the application of vector control DFIG is to achieve a decoupling between the quantities generating torque and flux. For this, we adjust the flux by (Ids or $I d r$ ), and torque by (Iqs or Iqr). Thus, the dynamics of DFIG will be reduced to that of a DC machine. This method can be outlined as shown in Fig 3. 


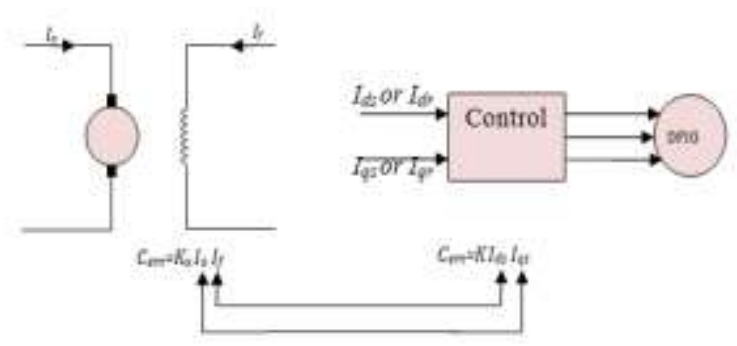

Fig. 3 Analogy between the Vector Control of DFIG and the Control of a DC Machine

The doubly fed induction generator model can be described by the next equations in the synchronous frame whose axis $d$ is aligned with the stator flux vector as shown in Fig. $4,\left(\phi_{d s}=\phi_{q s}\right)$ and $\left(\phi_{q s}=0\right)[7,21]$. By neglect stator resistances voltage will be:

$$
V_{d s}=0 \text { and } V_{q s}=V_{s}=\omega_{s} \phi_{s}
$$

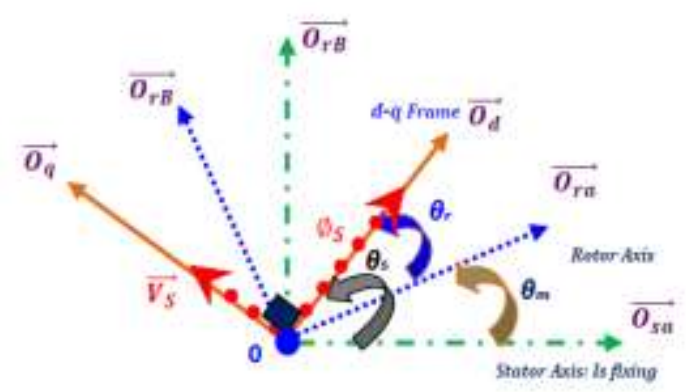

Fig. 4 Stator and rotor flux vectors

We driver to an uncoupled power control; where, $I d r$ controls the active power, and the reactive power is controlled by the direct component Ids [13] as shown in Fig 5:

$$
\begin{gathered}
P_{s}=-V_{s} \frac{M}{L_{s}} I_{q r} \\
Q_{s}=\left(\frac{\phi_{s} V_{s}}{L_{s}}-\frac{M}{L_{s}} V_{s} I_{d r}\right)=\left(\frac{V_{s}^{2}}{\omega_{s} L_{s}}-\frac{M}{L_{s}} V_{s} I_{d r}\right)
\end{gathered}
$$

The equations of the voltages according to the rotor currents are shown below (Fig. 5):

$$
\begin{gathered}
V_{d r}=R_{r} I_{d r}+L_{r} \sigma \frac{d I_{d r}}{d t}-L_{r} \sigma \omega I_{q r} \\
V_{q r}=R_{r} I_{q r}+L_{r} \sigma \frac{d I_{q r}}{d t}-L_{r} \sigma \omega I_{d r}+\frac{M}{L_{s}} \omega \phi_{s}
\end{gathered}
$$

With:

$$
\sigma=\left(1-M^{2}\right) / L_{s} L_{r}
$$

Where: $V d r, V q \mathrm{r}$ are rotor voltage; $R r$ is the rotor resistance; $L r, L \mathrm{~s}$ are the rotor inductances; $\mathrm{M}$ is mutual inductance; $\sigma$ is leakage factor. 


\section{THE SLIDING MODE CONTROL}

The main advantage of this control is its simplicity and robustness in spite of uncertainties in the system and external disturbances and, on the other hand, it needs relatively less information about the system $[15,16,19,20]$. The sliding mode control has three stages: Choice of surface, convergence condition and calculation of the control laws.

\subsection{Second Order Sliding Mode Control}

SMC is an interesting nonlinear method approach. Nevertheless, the biggest problem of this control is the chattering phenomenon which causes mischievous effects on the generator because of the discontinuous surveillance and that cause overheating and trigger unmodeled high frequency dynamics. SOMC is an attractive solution, it generalizes the sliding mode idea by going to a higher order time derivatives, which decrease chattering and avoid powerful mechanical efforts while maintaining advantages of the SMC [22], such as robustness under uncertainties. Aiming at achieving satisfactory tracking performance for Ps and Qs, the switching functions given next are adopted.

$$
\left\{\begin{array}{l}
S_{P}=e_{P}+c_{P} \int e_{P} d t \\
S_{Q}=e_{Q}+c_{Q} \int e_{Q} d t
\end{array}\right.
$$

The integral terms $c p$ sand $c Q$ are positive constant are added for steady-state errors elimination $[6,22]$. The voltage applied represented in the equation below:

$$
\left\{\begin{array}{l}
V_{d r}=V_{d r e q}+V_{d r n} \\
V_{q r}=V_{q r e q}+V_{q r n}
\end{array}\right.
$$

The system in reach the sliding surface with the help of the switching control Vdrn and Vqrn ; Vqreq and Vdreq are the equivalent control terms ,they make the system move along the sliding manifold and accelerate the response of the system while reducing the steady-state errors[21]. The equivalent control terms are derived by letting $S_{P}^{\&}=S_{Q}^{\mathcal{L}}=0$, the voltage to be applied to the rotor are expressed as:

$$
\left\{\begin{array}{l}
V_{\text {qreq }}=-\frac{L_{s} L_{r} \sigma}{M V_{s}}\left(P_{s_{-} r e f}^{\cdot}+c_{P}\left(P_{s_{-} r e f}-P_{s}\right)\right)+R_{r} I_{q r}-g w_{s} L_{r} \sigma I_{d r}-g \frac{M V_{s}}{L_{s}} \\
V_{d r e q}=-\frac{L_{s} L_{r} \sigma}{M V_{s}}\left(\dot{Q}_{s_{-} r e f}+c_{P}\left(Q_{s_{-} r e f}-Q_{s}\right)\right)+R_{r} I_{d r}-g w_{s} L_{r} \sigma I_{q r}
\end{array}\right.
$$

Thus;

$$
\begin{cases}V_{d r n}=y_{1}+B_{1}\left|e_{P}\right|^{\frac{1}{2}} \operatorname{sign}\left(e_{Q}\right) & \&=B_{2} \operatorname{sign}\left(e_{Q}\right) \\ V_{q r n}=y_{2}-B_{3}\left|e_{P}\right|^{\frac{1}{2}} \operatorname{sign}\left(e_{P}\right) & \&=-B_{4} \operatorname{sign}\left(e_{P}\right)\end{cases}
$$

Where B1, B2, B3 and B4 are constants.

\section{SIMULATION RESULTS}

In this section, simulation tests have been performed with the help of Matlab. A performance comparison with two different linear and nonlinear controllers "PI, SMC and SOSMC" will be introduced and discussed 
Wind speed shown in Fig (5) in order evaluates the designed control.

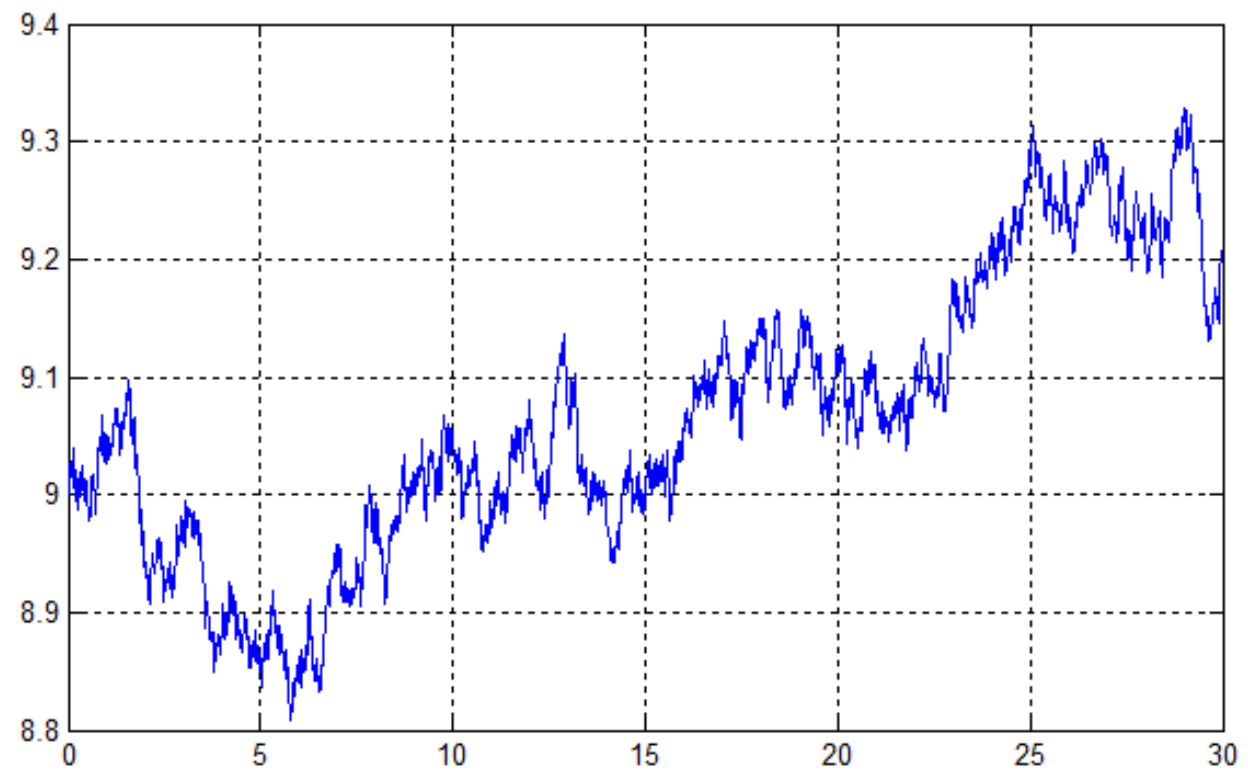

Fig. 5 Wind speed
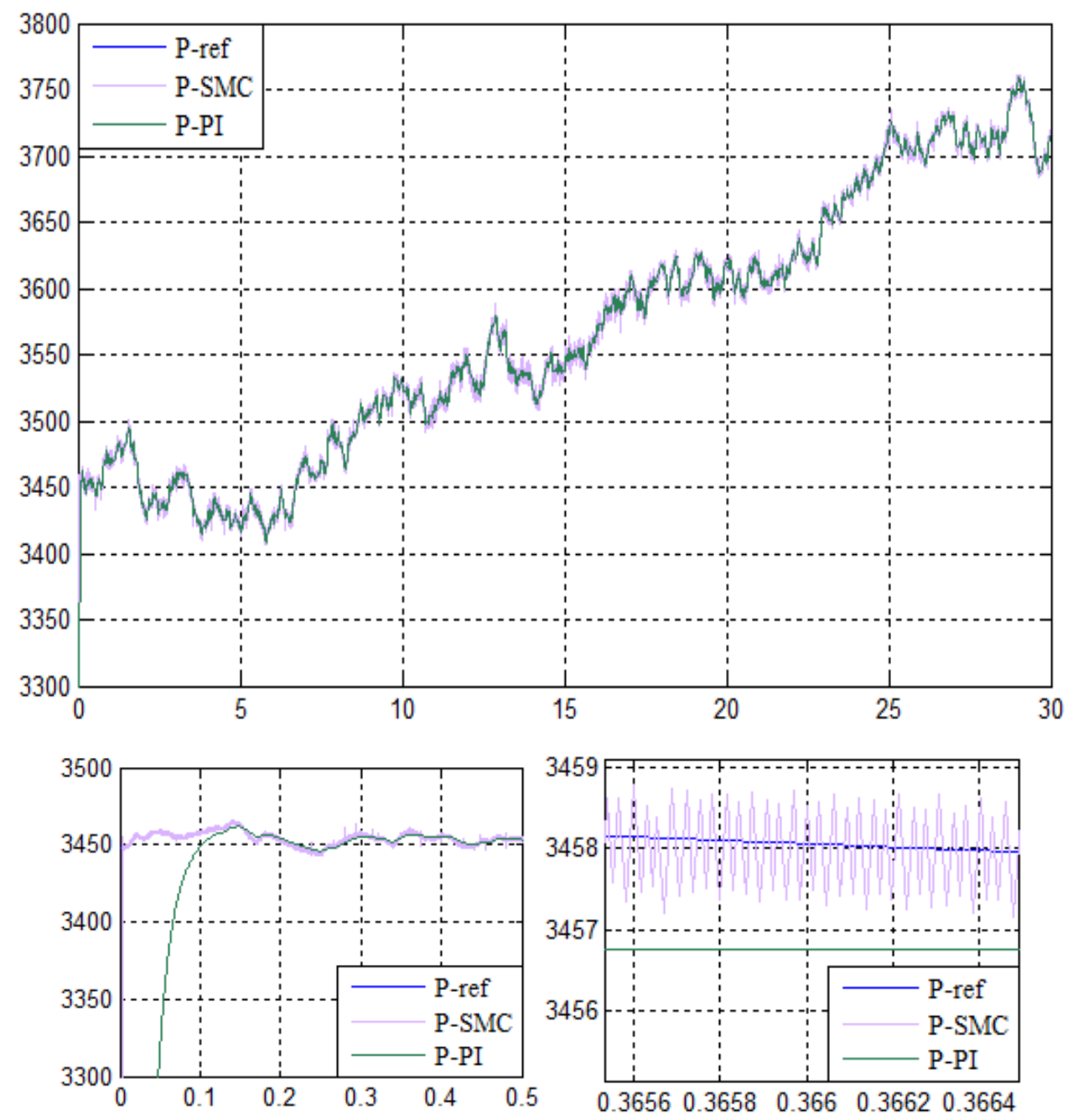

Fig. 6 Stator Active Power 

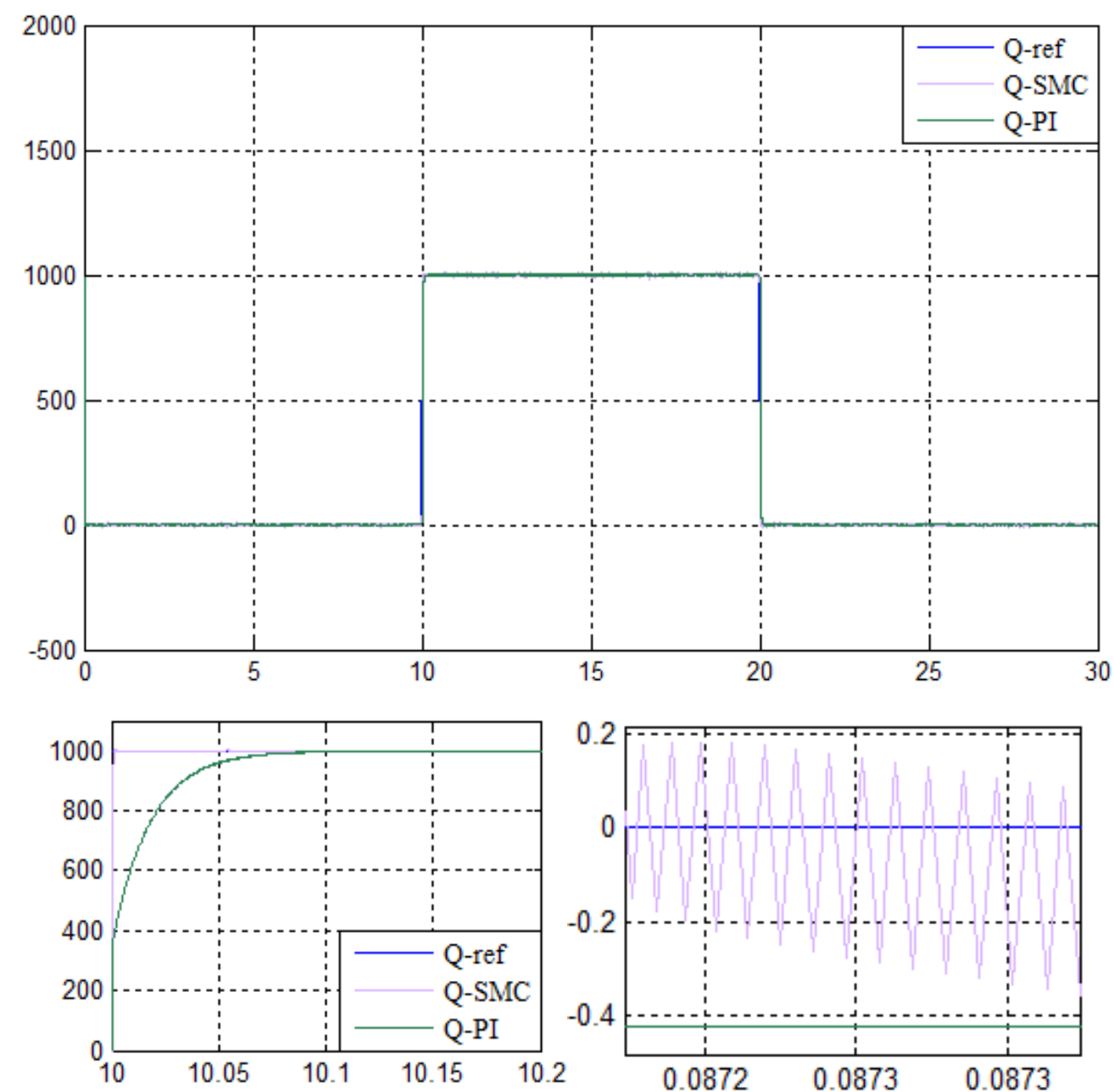

Fig. 7 Reactive Active power

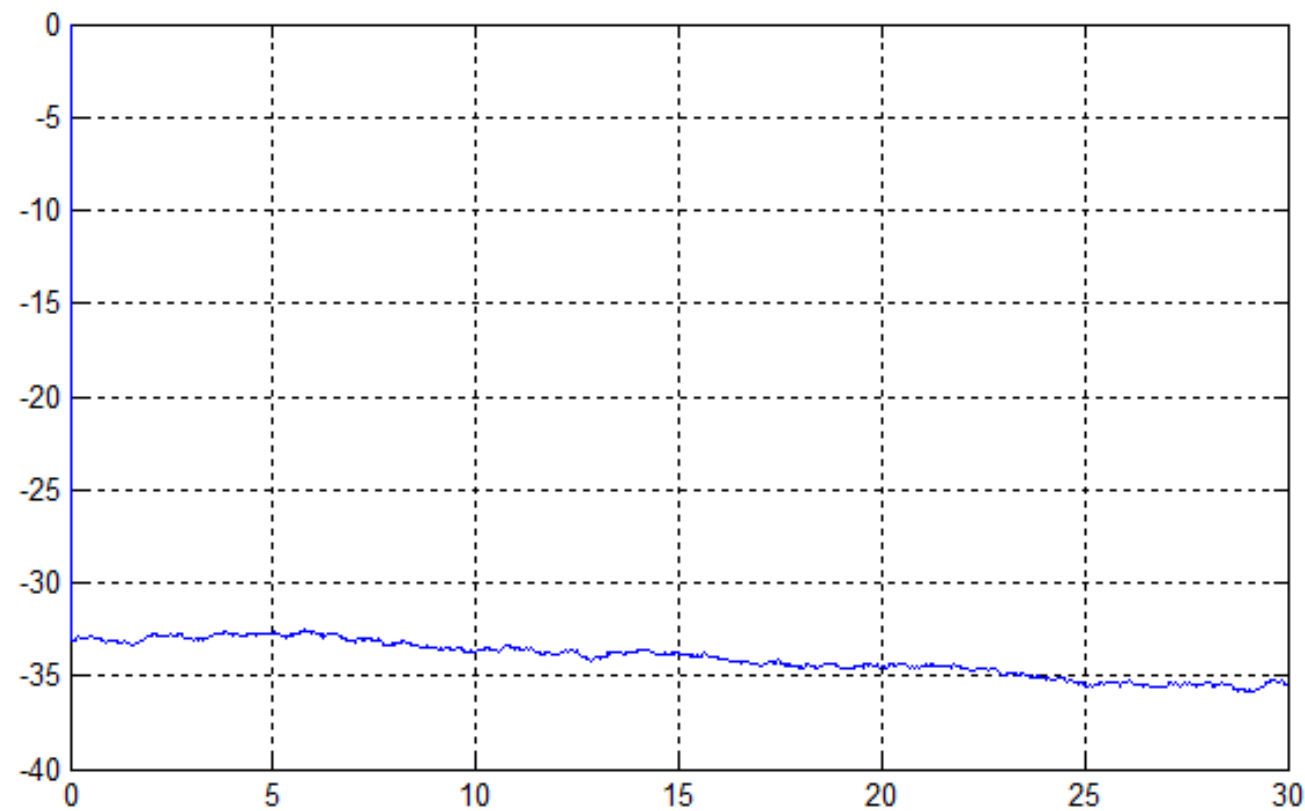

Fig. 8 Electromagnatique Couple 


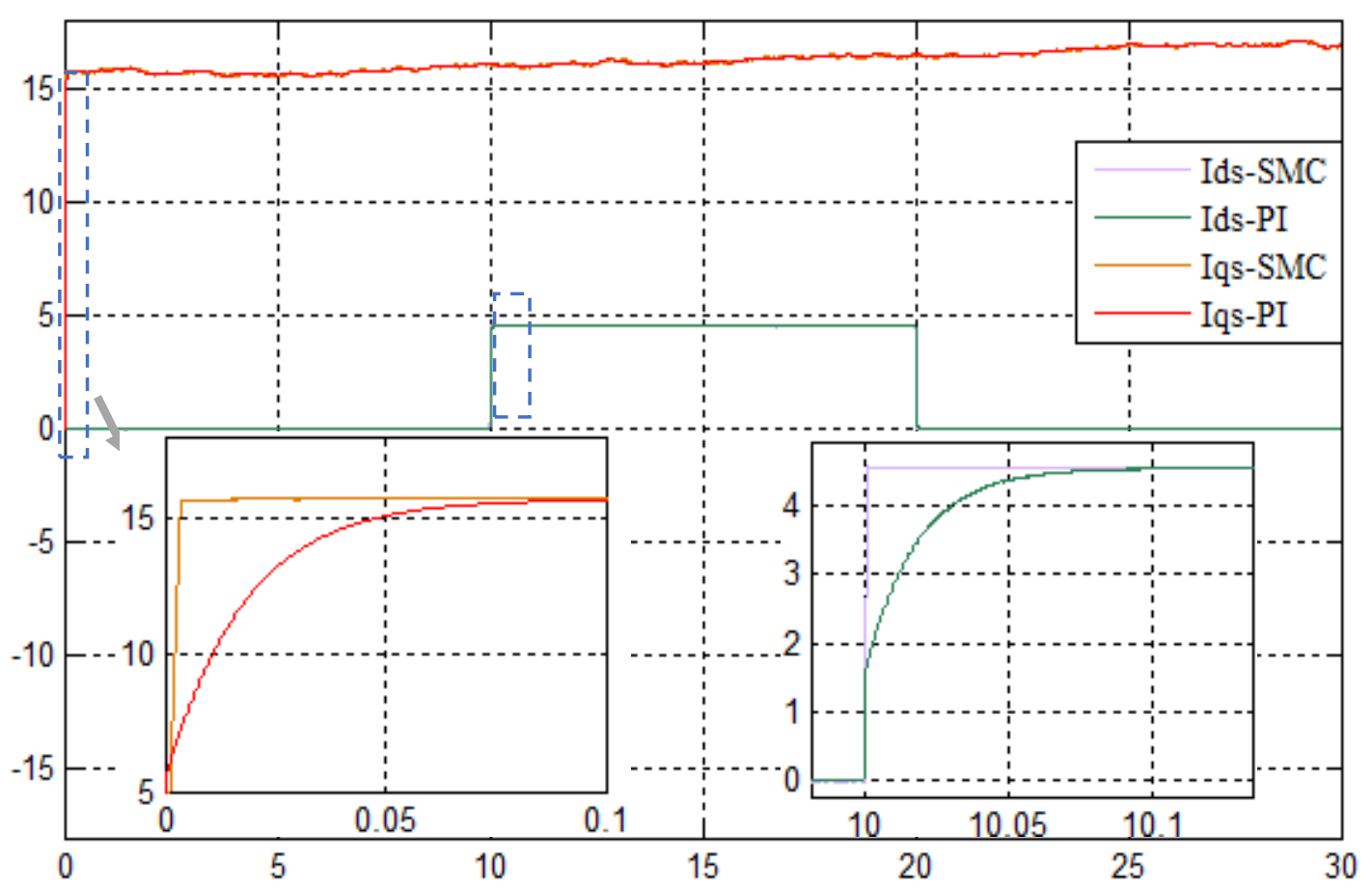

Fig. 9 Stator current components

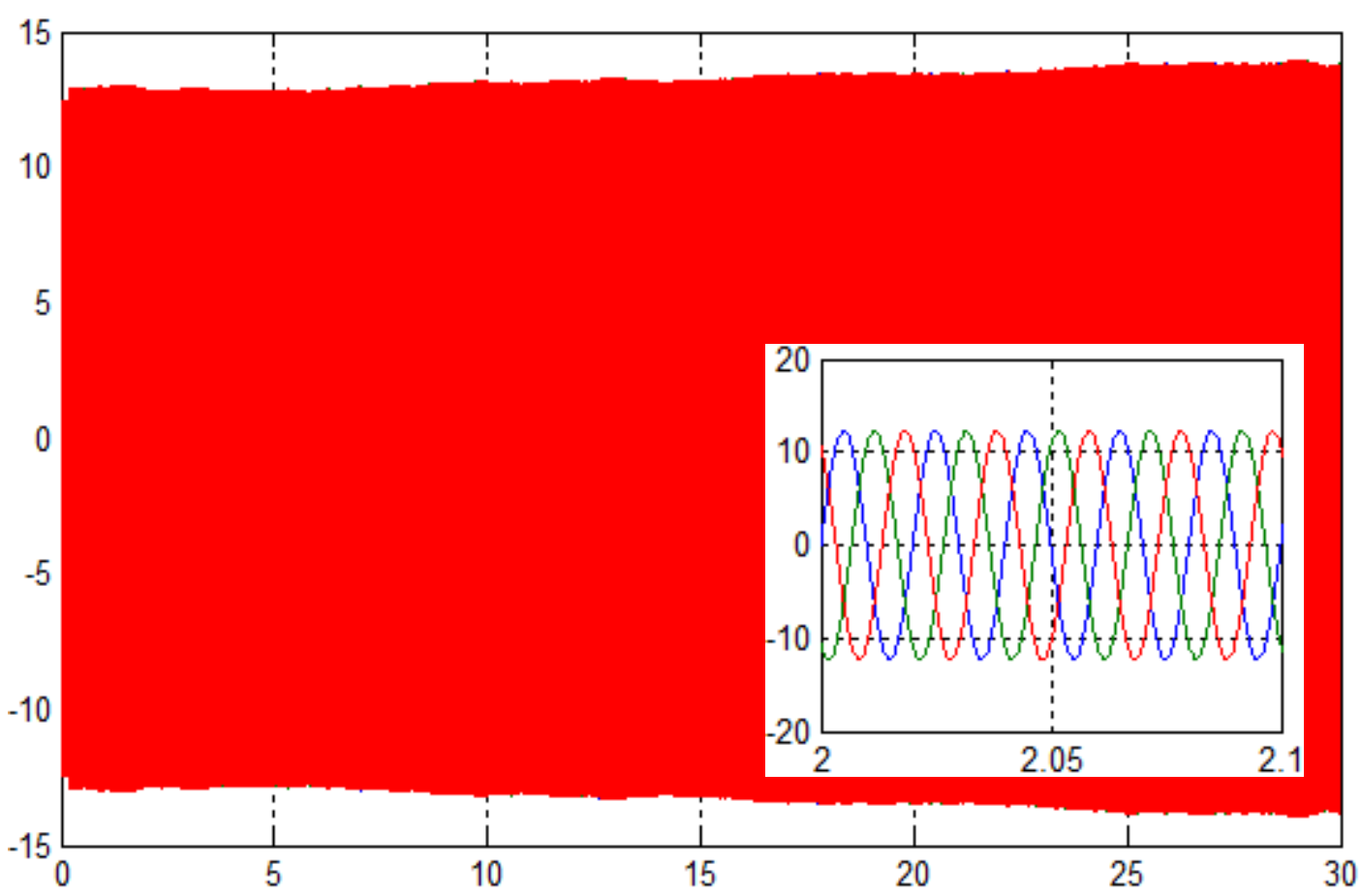

Fig. 10 Stator current

Fig 6-7 represent the stator active and reactive powers and its reference profiles using PI and SMC, we can notice that the dynamic response under the PI control is much slower than SMC control while SMC tracks almost perfectly their references. However, the first order sliding mode controller includes an appearance of perturbations which presented through the chattering phenomenon after zooming. To guarantee a unity power factor at the stator side, the reactive power must be maintained zero. 
The electromagnetic torque represented in Fig (8) is negative due to the generator operation. We can notice a great decoupling among the rotor and stator current components is obtained as shown in fig 9 which guarantee a decoupled powers control. Figure 10 displays the current waveform. It can be seen that the rotor is supplied with low variable frequency signals according to wind speed variations.

\section{CONCLUSION}

In order to ensure of the high performance, and to make the system insensible with the external disturbances and the parametric variations. A nonlinear controller has been developed for WT control. The proposed method was tasted and compared with other controllers. Simulation results show that the proposed controller provides a good efficiency, since it permits to track the optimum power quickly despite the speed wind changing. On the other hand, the stator power quantities provided show smooth waveforms, with good tracking indices. The chattering free improved performance of the SOSMC makes it superior to conventional SMC, and establishes its suitability for the system drive.

\section{REFERENCES}

[1] A. M. Kassem, K. M. Hasaneen and A. M. Yousef, "Dynamic modeling and robust power control of DFIG driven by wind turbine at infinite grid", International Journal of Electrical Power \& Energy Systems, vol. 44, no. (1), (2013), pp. 375-382.

[2] N. H. Saad, A. A. Sattar and A. E.-A. M. Mansour, "Low voltage ride through of doubly-fed induction generator connected to the grid using sliding mode control strategy", Renewable Energy, vol. 80, (2015), pp. 583-594.

[3] D. H. Phan and S. Huang, "Super-Twisting Sliding Mode Control Design for Cascaded Control System of PMSG Wind Turbine”, Journal of Power Electronics, vol. 15, no. (5), (2015), pp. 1358-1366.

[4] H. T. Jadhav and R. Roy, "A comprehensive review on the grid integration of doubly fed induction generator", International Journal of Electrical Power \& Energy Systems, vol. 49, (2013), pp. 8-18.

[5] S. Abdeddaim and A. Betka, "Optimal tracking and robust power control of the DFIG wind turbine", International Journal of Electrical Power \& Energy Systems, vol. 49, (2013), pp. 234-242.

[6] E. C. López and J. Persson, "High-Order Models of Doubly Fed Induction Generators", Wind Power in Power Systems, John Wiley \& Sons, Ltd., (2012), pp. 849-864.

[7] A. Hansen, P. Sø rensen, F. Blaabjerg and F. Iov, "Centralised power control of wind farm with doubly fed induction generators", Renewable Energy, vol. 31, no. (7), (2006), pp. 935-951.

[8] N. D. Caliao, "Dynamic modelling and control of fully rated converter wind turbines", Renewable Energy, vol. 36, no. 8, (2011), pp. 2287-2297.

[9] F. E. V. Taveiros, L. S. Barros and F. B. Costa, "Back-to-back converter state-feedback control of DFIG (doubly-fed induction generator)-based wind turbines", Energy, vol. 89, (2015), pp. 896-906.

[10] T. Ahmed, K. Nishida and M. Nakaoka, "A Novel Stand-Alone Induction Generator System for AC and DC Power Applications”, IEEE Transactions on Industry Applications, vol. 43, no. 6, (2007), pp. 14651474.

[11] J. B. Alaya, A. Khedher and M. F. Mimouni, "Nonlinear vector control strategy applied to a variable speed DFIG generation system”, Eighth International Multi-Conference on Systems, Signals \& Devices, (2011), pp. 1-8.

[12] Y. Shtessel, C. Edwards, L. Fridman and A. Levant, "Sliding Mode Control and Observation", Springer New York, (2013).

[13] Z. Song, T. Shi, C. Xia and W. Chen, "A novel adaptive control scheme for dynamic performance improvement of DFIG-Based wind turbines", Energy, vol. 38, no. 1, (2012), pp. 104-117.

[14] B. Yang, L. Jiang, L. Wang, W. Yao and Q. H. Wu, "Nonlinear maximum power point tracking control and modal analysis of DFIG based wind turbine", International Journal of Electrical Power \& Energy Systems, vol. 74, (2016), pp. 429-436.

[15] M. J. Morshed and A. Fekih, "A new fault ride-through control for DFIG-based wind energy systems", Electric Power Systems Research, vol. 146, (2017), pp. 258-269.

[16] J. G. Njiri and D. Söffker, "State-of-the-art in wind turbine control: Trends and challenges", Renewable and Sustainable Energy Reviews, vol. 60, (2016), pp. 377-393.

[17] G. Abad, J. López, M. A. Rodríguez, L. Marroyo and G. Iwanski, "Direct Control of the Doubly Fed Induction Machine", Doubly Fed Induction Machine, John Wiley \& Sons, Inc., (2011), pp. 363-477. 
[18] A. Luna, F. K. A. Lima, P. Rodriguez, E. H. Watanabe and R. Teodorescu, "Comparison of power control strategies for DFIG wind turbines", 2008 34th Annual Conference of IEEE Industrial Electronics, (2008), pp. 2131-2136.

[19] M. Benkahla, R. Taleb and Z. Boudjema, "Comparative Study of Robust Control Strategies for a DfigBased Wind Turbine", International Journal of Advanced Computer Science and Applications, vol. 7, no. (2), (2016), pp. 455-462.

[20] S. Li, T. A. Haskew, R. P. Swatloski and W. Gathings, "Optimal and Direct-Current Vector Control of Direct-Driven PMSG Wind Turbines", IEEE Transactions on Power Electronics, vol. 27, no. (5), (2012), pp. 2325-2337.

[21] E. Bounadja, A. Djahbar, R. Taleb and Z. Boudjema, "A new adjustable gains for second order sliding mode control of saturated DFIG-based wind turbine", AIP Conference Proceedings, vol. 1814, no. (1), (2017), 020009.

[22] X. Zhu, S. Liu and Y. Wang, "Second-order sliding-mode control of DFIG-based wind turbines", (2014). 
International Journal of Control and Automation Vol. 12, No. 5 (2019) 